\title{
REGISTRO DA MEMÓRIA AUDIOVISUAL DO COMBATE À DOENÇA DE CHAGAS NO MUNICÍPIO DE CÁSSIA DOS COQUEIROS, SÃO PAULO
}

\author{
*Afonso Dinis Costa Passos
}

\section{RESUMO}

Algumas das mais relevantes contribuições ao combate à doença de Chagas no Brasil foram feitas pelo professor José Lima Pedreira de Freitas (I9I7-1966), entre I947 e I966. Incluem-se aí o desenvolvimento de técnicas sorológicas, investigações sobre biologia dos triatomíneos e estudos clínicos e epidemiológicos. Todavia, a sua mais importante contribuição reside no desenvolvimento do chamado expurgo seletivo, técnica de controle de triatomíneos a partir de aplicações de inseticidas feitas seletivamente nos domicílios, idealizada e desenvolvida em Cássia dos Coqueiros, Estado de São Paulo. Este procedimento representou uma revolução conceitual, por combinar elevada eficácia com redução de custos e de agressão ao meio ambiente, razões que levaram a sua incorporação em todo o continente americano. A sua autoria, contudo, foi perdida na memória da Saúde Pública brasileira, sendo muito raramente lembrada a sua associação com Cássia dos Coqueiros e com o seu idealizador. Este projeto visou resgatar a memória da participação do professor Pedreira de Freitas no combate à doença de Chagas, mediante a elaboração de um documentário envolvendo o depoimento de antigos moradores e de ex-professores da Faculdade de Medicina de Ribeirão Preto, que com ele tiveram contato próximo ao longo da sua trajetória profissional.

Palavras-chave: Doença de Chagas. Controle. Cássia dos Coqueiros.

\begin{abstract}
Some of the major advances in Chagas's disease control in Brazil should be credited to Professor José Lima Pedreira de Freitas (I9I7-I966). From I947 to I966, his contributions included development of serological techniques, investigations on the biological aspects of the triatomines, as well as clinical and epidemiological studies. His most relevant achievement, however, was a technique for controlling triatomines based upon selective spraying of insecticide only within infested houses, which was thought and developed in Cassia dos Coqueiros, a small village in the state of São Paulo, Brazil. Named selective purge, this revolutionary technique combined high efficacy, low cost and less environmental risks, which caused it to be largely adopted in the American continent. Unfortunately, its authorship has been missed within the brazilian public health memory, being its association with Cássia dos Coqueiros and Pedreira de Freitas rarely mentioned. The present project aimed at recovering the memory of professor Freitas's struggle against Chagas's disease, by developing a documentary involving participation of old local inhabitants and former professors of the Medical School which worked closely to him.
\end{abstract}

Key words: Chagas's disease. Control. Cássia dos Coqueiros.

* Professor do Departamento de Medicina Social da Faculdade de Medicina de Ribeirão Preto, da Universidade de São Paulo. Av. dos Bandeirantes, 3900 - I4049-900-Ribeirão Preto-SP - e-mail: apassos@fmrp.usp.br 


\section{INTRODUÇÃO}

A doença de Chagas representa ainda hoje um dos mais importantes problemas sanitários em extensas áreas da América Latina. Estima-se que aproximadamente 90 milhões de pessoas vivam em áreas expostas ao risco, e que cerca de I 8 a 25 milhões de indivíduos estejam infectados (HAYES \& SCHOFIELD, I990; UNDP/WORLD BANK/WHO, I990). Em nosso país, a endemia chagásica ocupa ainda posição de destaque no quadro sanitário em virtude do grande contingente de infectados crônicos que a adquiriram em décadas passadas, quando a transmissão se fazia de modo intenso em regiões carentes, habitadas por indivíduos social e economicamente marginalizados (SILVEIRA, 2000). Na verdade, o combate sistematizado à doença de Chagas somente passou a ser realizado em toda a área endêmica brasileira a partir de I983, sendo seguido de enormes avanços verificados em anos recentes. Exemplo eloquente pode ser encontrado na certificação internacional de eliminação da transmissão natural pelo Triatoma infestans, obtida pelo Brasil, em 2006. Outra indicação dos avanços conseguidos vem do Inquérito Sorológico Nacional sobre Doença de Chagas, ainda em andamento em uma amostra representativa de toda a área rural brasileira. Com cerca de IIO mil amostras já coletadas entre menores de cinco anos de idade, os seus resultados preliminares mostram que a transmissão da doença encontra-se hoje praticamente interrompida no território nacional. O impacto dessa realidade pode ser avaliado com base em análise do programa brasileiro do controle da doença de Chagas (DARIUSH, I998), que chegou à estimativa de que, entre I975 e I995, teriam sido prevenidas 2.339.000 novas infecções e 337.000 óbitos, ou II.486.000 anos de vida ajustados para incapacidade.

O extraordinário avanço no controle de uma endemia desse porte representa uma das maiores conquistas na história da saúde pública brasileira. Na sua raiz, podem ser encontradas as participações de inúmeros profissionais, médicos ou não, que em diferentes momentos concentraram energia na definição e implementação de metodologias de campo capazes de fazer frente ao problema. Inquestionavelmente, um desses profissionais foi o professor José Lima Pedreira de Freitas que, na condição de professor de $\mathrm{Pa}$ rasitologia da Faculdade de Medicina da Universidade de São Paulo, dedicou-se, a partir de I944, a estudar a doença de Chagas. Tendo tomado conhecimento dos elevadíssimos níveis de transmissão que então ocorriam na região nordeste do estado, mais particularmente no município de Cajuru, o professor Pedreira instalou, já em 1947, no então Distrito de Cássia dos Coqueiros, um posto de estudo da moléstia de Chagas. Importante salientar que a presença do professor em Cássia dos Coqueiros antecedeu em cinco anos a criação da própria Faculdade de Medicina de Ribeirão Preto (FMRP-USP), ocorrida em 1952, e à qual ele viria se juntar a partir do seus primórdios, tendo sido o criador e primeiro chefe do Departamento de Higiene e Medicina Preventiva, agora Departamento de Medicina Social. Embrião da atual estrutura do Centro Médico Social Comunitário Pedreira de Freitas, mantido pela FMRP como campo de treinamento de seus alunos de graduação, esse laboratório permitiu a realização de inúmeros estudos clínicos, epidemiológicos e profiláticos de extrema importância no avanço do conhecimento sobre a doença e sua profilaxia.

Apesar desse enorme rol de contribuições, percebe-se que o nome do professor Pedreira de Freitas é raramente lembrado nas discussões envolvendo a doença de Chagas. Lamentavelmente, a sua lembrança vai sendo apagada da memória sanitária brasileira, o que constitui uma perda irreparável, com a qual a Universidade não pode concordar. Resgatar a memória do seu trabalho e das suas conquistas torna-se uma obrigação da atual geração de profissionais ligados à Faculdade de Medicina de Ribeirão Preto, ainda mais por ocasião do centenário da descoberta e descrição da doença, que se comemora em 2009.

Assim, esta iniciativa teve o objetivo de resgatar e registrar a memória audiovisual relativa ao combate à doença de Chagas levado a efeito no município de Cássia dos Coqueiros, estado de São Paulo, pelo professor José Lima Pedreira de Freitas.

\section{METODOLOGIA}

Foram identificados e contatados oito antigos moradores de Cássia dos Coqueiros e seis ex-professores da Faculdade de Medicina de Ribeirão Preto, que, entre I947 e I966, tiveram contato próximo com o professor Pedreira de Freitas, auxiliando-o nas atividades de combate aos triatomíneos e de prevenção da doença de Chagas. Com a participação de dois 
profissionais vinculados à concessionária de uma rede de televisão de abrangência nacional, ambos com larga experiência na realização de documentários, foram gravados os depoimentos dessas $\mathrm{I} 4$ pessoas. Um docente atual da Faculdade de Medicina participou em diferentes inserções, chamando a atenção para a relevância histórica e sanitária das principais atividades realizadas à época.

Em complemento aos depoimentos, foram gravadas cenas externas da região rural do município, retratando áreas que haviam sido alvo de intensos trabalhos de combate aos triatomíneos entre 1947 e I966. Também mereceram destaque locais de interesse histórico, tais como velhas construções onde funcionaram laboratórios de campo em áreas distantes do núcleo urbano. Todo esse material foi editado e narrado por profissionais vinculados à mesma rede de televisão na qual trabalham os cinegrafistas que gravaram as imagens. No total, foram realizadas I6 horas de gravação em minidvd.

\section{RESULTADOS}

O resultado imediato foi um documentário de 50 minutos de duração em formato digital, narrado e comentado, que retrata os principais momentos das conversas feitas com os antigos moradores e professores entrevistados e mostra alguns aspectos das áreas rurais nas quais foram desenvolvidas atividades de combate à doença de Chagas. Esse material foi incorporado ao acervo da Faculdade de Medicina de Ribeirão Preto, para divulgação interna e externa.

Como resultado a médio prazo e com base no material coletado, planeja-se a elaboração de um livro que consolide a documentação do combate à moléstia de Chagas em Cássia dos Coqueiros.

\section{DISCUSSÃO}

As principais contribuições do professor $\mathrm{Pe}$ dreira no combate à doença de Chagas incluem o desenvolvimento da técnica quantitativa de fixação do complemento para o diagnóstico sorológico, realização de diversos inquéritos que mostraram a importância da doença no Brasil, estudos da transmissão congênita e por via transfusional, uso de violeta de genciana como agente neutralizante do Tripanossoma cruzi no sangue a ser transfundido, estudo das formas nervosas da doença, avanços no conhecimento da biologia dos triatomíneos envolvidos na transmissão e testes de eficácia de diferentes inseticidas (YAZLLE-ROCHA et al., I99I).

Do ponto de vista de prevenção, todavia, a contribuição mais fundamental do professor Pedreira foi o desenvolvimento do assim chamado "expurgo seletivo". Objeto da sua tese de livre docência (PEDREIRA DE FREITAS, I963) tal técnica consiste na execução de aplicações de inseticidas feitas seletivamente nos domicílios da área endêmica, em contrapartida à aplicação repetida e generalizada, preconizada até então. O expurgo seletivo, pensado e desenvolvido em Cássia dos Coqueiros, representou uma verdadeira revolução na metodologia de trabalho de campo, uma vez que propicia redução de custos e de agressão ao meio ambiente, ao mesmo tempo em que mantém resultados altamente satisfatórios no controle de triatomíneos. Tal metodologia foi paulatinamente incorporada aos programas nacionais de combate à doença de Chagas, sendo hoje adotada em praticamente todo o continente latino-americano.

Não obstante sua relevância, a autoria dessa técnica revolucionária perdeu-se ao longo do tempo, não sendo mencionada em quase nenhum fórum de discussão sobre a doença de Chagas. O documentário aqui apresentado resgata essa verdade histórica, tanto pelo depoimento dos ex-docentes que vivenciaram o desenvolvimento do processo, como, de modo particular, pelo testemunho de antigos moradores que colaboraram na execução dos trabalhos de campo, montando as estações experimentais na área rural do município. Tais estações consistiam de domicílios abandonados ou de construções especificamente erigidas para o experimento, onde colônias de triatomíneos eram submetidas a diferentes metodologias de aplicação de inseticidas com ação residual.

No seu conjunto, os depoimentos e as imagens resgatam aspectos de grande importância histórica e praticamente perdidos no tempo, uma vez que boa parte deles nunca havia sido registrada formalmente, existindo apenas na memória de testemunhas oculares, cuja faixa etária os situa próximos da oitava ou nona década de vida. Vista assim, a confecção do documentário enriquece a história do combate à doença de Chagas em nosso país, representando contribuição 
valiosa à memória sanitária nacional em um momento em que se celebra o centenário da mais extraordinária conquista científica feita por um pesquisador brasileiro. Para a Faculdade de Medicina de Ribeirão Preto da Universidade de São Paulo a recuperação dessa memória restabelece uma verdade histórica e atribui o justo mérito a um dos mais atuantes professores que por ela passaram.

\section{REFERÊNCIAS BIBLIOGRÁFICAS}

DARIUSH, A. Análise de Custo-Efetividade do Programa de Controle da Doença de Chagas no Brasil: Relatório Final. Brasília: OPAS, I998.

HAYES, R. J.; SCHOFIELD, C. J. Estimación de las tasas de incidencia de infecciones y parasitosis crónicas a partir de la prevalencia: La enfermedad de Chagas en América Latina. Boletín de la Oficina Sanitaria Panamericana. v. I08, p. 308-316, 1990.

PEDREIRA DE FREITAS, J. L. Importância do expurgo seletivo dos domicílios e anexos para a profilaxia da moléstia de Chagas pelo combate aos triatomíneos. Ribeirão Preto, 1963, 78p. Tese (Catedrático em Higiene e Medicina Preventiva). Faculdade de Medicina de Ribeirão Preto, Universidade de São Paulo.

SILVEIRA, A. C. Current situation with Chagas disease vector control in the Americas. Cad. Saúde Pública. v. I6 (Supplement 2), p. 35-42, 2000.

UNDP/ WORLD BANK/ WHO (United Nations Development Program/ World Bank/ World Health Organization). Special Programme for Research and Training in Tropical Diseases. TDR News. v. 34, p. 3-34, I990.

YAZLLE-ROCHA, J. S.; RUFFINO-NETTO, A.; NOGUEIRA, J. L. Departamento de Medicina Social. 40 anos da FMRP-USP - o Departamento de Medicina Social. Medicina, Ribeirão Preto. v. 25, p.74-84, I99I. 